\title{
Effects of Gait Training Using a Robot for Balance in Total Hip Arthroplasty Patients after Bilateral Avascular Necrosis: A Case Study
}

\author{
So-Yeong Kim¹, Byeong-Geun Kim², Woon-Su Cho², Chi-Bok Park² \\ 'Department of Physical Therapy, Graduate School, Nambu University, Gwangju, Republic of Korea; ${ }^{2}$ Department of Physical Therapy, Nambu \\ University, Gwangju, Republic of Korea
}

Purpose: This study sought to investigate the effects of robot-assisted gait training on balance in total hip arthroplasty (THA) patients after bilateral avascular necrosis (AVN).

Methods: This case study in two patients utilized an 'A-B-A' single-subject experimental design that included five days of pre-intervention, followed by five days of intervention, and five days of post-intervention. The intervention involved the use of a standing inclined robot (R-bot) for 15 minutes. The outcome measures were evaluated using the Functional Reaching Test (FRT), Time Up to Go (TUG), and the Modified One Leg Standing Test (OLST).

Results: Patient 1 showed improvement based on data gathered from baseline $A$ to intervention period $B$, with results as follows: FRT improved from $27.7 \mathrm{~cm}$ to $41.28 \mathrm{~cm}$, OLST LT from 14.03 seconds to 67.37 seconds, OLST RT from 2.94 seconds to 35.97 seconds, and TUG from 12.96 seconds to 7.82 seconds. Patient 2 also showed improvement from baseline $A$ to intervention period $B$, with results as follows: FRT improved from $17.18 \mathrm{~cm}$ to $24.3 \mathrm{~cm}$, OLST LT from 11.53 seconds to 52.01 seconds, OLST RT from 12.99 seconds to 62.19 seconds, and TUG from 27.31 seconds to 12.99 seconds.

Conclusion: Based on the results of this study, robotic rehabilitation during the early stages after surgery is effective for promoting balance in patients who have undergone THA due to bilateral AVN.

Keywords: Avascular necrosis, Total hip arthroplasties, Balance, Robot rehabilitation

\section{서 론}

넙다리뼈 머리 무혈성 괴사(avascular necrosis of femoral head, AVN)는 미국에서 매년 20,000-30,00명 진단을 받고 있는 것으로 추정되며, 미 국에서 시행되는 인공엉덩관절성형술(total hip arthroplasties, THA) 중 $10 \%$ 에 해당된다. ${ }^{1} \mathrm{AVN}$ 은 35 세에서 45 세 사이 젊은 성인에게 주로 발생된다. ${ }^{2}$ 그리고 남성이 여성보다 3 배 이상 더 많은 영향을 받으며, 양측으로 발생되는 $\mathrm{AVN}$ 이 전체의 $75 \%$ 를 차지한다. 확실한 원인은 밝혀지지 않았지만 과다한 음주, 스테로이드의 오남용, 외상으로 인 한 골절 및 탈구 등을 원인으로 보고 있다. ${ }^{4} \mathrm{AVN}$ 이 진행된 환자의 대 다수는 THA를 진행하며, ${ }^{5}$ 수술 후 에는 의사, 간호사, 물리치료사, 작 업치료사, 사회복지사의 다학제적 접근(multidisciplinary approach)이 필요하다. ${ }^{6}$
관절 성형술(joint arthroplasty)은 팔다리의 모든 관절에서 시행될 수 있으며 그 중에서도 엉덩관절과 무릎관절이 가장 흔하다. ${ }^{7 H A}$ 는 일반적으로 65 세 이상의 노인에게 시행하는 것이 권장된다. 하지만 $\mathrm{AVN}$ 으로 인한 THA는 활동이 큰 젊은 연령대인 48세에서 가장 많이 시행되고 있으며, 이는 수술의 $50 \%$ 이상을 차지한다. ${ }^{8} \mathrm{THA}$ 환자는 수 술 후 균형의 결함이 발생할 수 있으므로, ${ }^{9} \mathrm{THA}$ 후 재활은 필수적이 다. ${ }^{10}$ 재활 방법 중 체중 부하를 통한 엉덩관절 운동치료는 관절가동 범위와 보행능력을 향상시키며, 엉덩관절 운동치료는 독립적인 기능 훈련과 일상생활로의 복귀를 위한 대표적인 치료이다." 그러므로 THA 후 적용되어지는 물리치료 중재는 매우 중요하다.

THA 후 중재로 운동치료 방법이 가장 많이 사용되고 있다.12 운동 치료 방법으로는 저항 운동, ${ }^{13}$ 가정 기반 운동, ${ }^{14}$ 고유 수용성 감각 운 동, ${ }^{15}$ 심혈관 및 유연성 운동 ${ }^{16}$ 등 다양한 방법의 운동이 있다. 그러나
Received Sep 15, 2021 Revised Oct 28, 2021

Accepted Oct 30, 2021

Corresponding author Chi-Bok Park

E-mail oasislovept@hanmail.net
Copylight (C2021 The Korean Society of Physical Therapy

This is an Open Access article distribute under the terms of the Creative Commons Attribution Non-commercial License (https:// creativecommons.org/license/by-nc/4.o.) which permits unrestricted non-commercial use, distribution, and reproduction in any medium, provided the original work is properly cited. 
THA 환자에게 중재하는 근력강화 운동, 유산소 운동, 기능적 운동 에 대한 타당성이 낮으며 효과에 대한 신뢰가 부족하다는 단점이 있 다. ${ }^{17}$ 이런 단점을 보완할 수 있는 방법으로는 로봇 재활 방법이 있다. 로봇 재활은 환자가 필요로 하는 움직임을 제공할 수 있으며, 정확한 운동은 효과적인 움직임을 만들어 낼 수 있다.18

로봇 재활은 뇌병변 환자에게 사용되고 있고, ${ }^{19,20}$ 인공무릎관절치 환술 환자에게도 사용되고 있다. ${ }^{16,21-23}$ 최근에 엉덩관절 관절염 환자 에게 웨어러블 로봇 재활을 실시한 하나의 사례연구가 보고되었다. ${ }^{24}$ 선행연구에서 사용된 로봇은 환자가 엉덩관절에 웨어러블 로봇을 착용하여 움직임에 보조를 받는 로봇이므로, 엉덩관절에 몸통의 체 중 부하를 지지해줄 수 없어 안전성에 한계가 있다. 엉덩관절 수술 환 자에게 로봇 재활을 적용한 연구는 부족한 실정이며, 특히 $\mathrm{AVN}$ 으로 양측 THA를 한 환자에게 로봇 재활을 적용한 사례는 확인할 수 없 었다. 따라서 본 연구의 목적은 AVN으로 인한 양측 THA 시행한 환 자에게 로봇을 이용한 보행 훈련이 균형에 어떤 영향을 미치는지 사 례를 제시하고자한다.

\section{연구 방법}

\section{1. 연구 설계}

본 연구에서는 A-B-A' 단일 사례 연구 설계를 사용하였다. A와 $A^{\prime}$ 는 기초선 기간이었으며, $\mathrm{B}$ 는 기립 경사 로봇을 통한 보행 훈련을 적용 한 중재기간이다. 연구 기간은 총 15 일 진행하였고, 첫 번째 기초선(A) 은 5일, 중재 기간(B)은 기립경사로봇을 통한 보행 훈련 5일, 두 번째 기초선(A')은 5 일 수행하였다. 중재 후 매일 동일한 측정을 3 회 반복해 시행하였다.

\section{2. 연구 대상자}

본 연구의 대상은 2021년 6월과 7월에 광주의 G 재활 병원에 내원한
30 대 남성과 여성 총 2 명으로 일반적 특성은 Table 1과 같다. 연구를 수행하기 전에 연구대상자에게 본 연구의 취지에 대하여 충분히 설 명하였고, 연구 참여에 대한 자발적 동의를 받은 후에 연구를 진행하 였다.

\section{3. 측정방법 및 도구}

1) 기능적 팔 뻗기 검사(Functional Reaching Test, FRT)

대상자는 거울 옆에 두 발을 어깨 넓이로 지면에 고정 한 채 바른 자 세로 서 있는다. 양 어깨를 $90^{\circ}$ 굽힘 하고 팔꿈치 관절을 폄 상태에서 손가락을 핀다. 이 상태에서 얼마만큼 앞으로 나아갈 수 있는지를 측 정한다. 연구자가 대상자에게 주의사항을 설명한 후, 측정된 값에서 처음 시작 자세의 특정 값을 빼준 값으로 사용한다. 기능적 팔 뺃기 검사의 신뢰도는 0.81 이다. ${ }^{25}$ 본 연구에서 사용된 측정자 간 신뢰도는 $\operatorname{ICC}(3,3)=1$ 이다.

2) 의자에서 일어나 걷기 검사(Time Up to Go test, TUG) 등받이가 있는 의자에 대상자는 바른 자세로 앉아 있는다. 출발 신호 에 맞춰 독립보행으로 $3 \mathrm{~m}$ 거리의 반환점을 돌아 안전하게 의자로 다 시 돌아 앉는 시점까지의 소요시간을 측정한다. 의자에서 일어나 걷 기 검사 신뢰도는 0.56 이다. ${ }^{26}$ 본 연구에서 사용된 측정자 간 신뢰도는 $\operatorname{ICC}(3,3)=0.942$ 이다.

3) 변형된 한발 서기 검사(Modified One Leg Standing Test, OLST) 두 눈을 뜬 채 두 발을 편평한 지면에 고정한다. 왼쪽과 오른쪽을 번 갈아 가며 한발씩 들기를 시행했다. 한발이 지면에 고정된 상태에서 반대편 다리는 지면에서 $10 \mathrm{~cm}$ 높이로 들고 흔들릴지라도 발이 땅에 떨어지지 않으며 다른 사물을 잡지 않고 버틸 수 있는지를 확인한다. 다음 테스트까지 30 초의 휴식시간을 갖는다. 한발 서기 검사의 신뢰 도는 0.75 이다. ${ }^{27}$ 본 연구에서 사용된 측정자 간 신뢰도 왼쪽은 ICC

Table 1. General characteristics of the case

\begin{tabular}{|c|c|c|}
\hline & 1 Case & 2 Case \\
\hline \multirow[t]{6}{*}{ History } & $\mathrm{M} / 38,170 \mathrm{~cm}, 78.5 \mathrm{~kg}$ & $\mathrm{~F} / 38,162 \mathrm{~cm}, 60 \mathrm{~kg}$ \\
\hline & Office job & Office job \\
\hline & HTN & Bilateral carpal tunnel syndrome 1 year ago \\
\hline & & Lt. shoulder LOM: flexion 120, abduction 90, external rotation 5, VAS: 5 \\
\hline & $\begin{array}{l}\text { Medication atoren tab } 10 \mathrm{mg} \text {, lowdin tab } 5 \mathrm{mg} \text {, } \\
\text { telmican plus tab } 80 / 12\end{array}$ & $\begin{array}{l}\text { Medication ultracet er semi tab, celebrex cap } 200 \text { mg, lanston LFDT tab } \\
15 \text { mg, mediaven I tab, hinechol tab } 25 \text { mg, feroba-you sr tab }\end{array}$ \\
\hline & Dignosis 2003, Operation 2021. 06. 06 & Dignosis 2020.08, Operation 2021. 07. 05 \\
\hline \multirow[t]{4}{*}{ Outcome measure } & HOOS 28 score & HOOS 11 score \\
\hline & Modified harris hip score: 62/79 & Modified harris hip score 25/79 \\
\hline & IHОТ33: 135/330 & ІНОТЗ3: 37/330 \\
\hline & BBS: $42 / 56$ & BBS: $31 / 56$ \\
\hline
\end{tabular}

HOOS: Hip Dysfunction and Osteoarthritis Score, IHOT33: International Hip Outcome Tool, BBS: Berg Balance Scales. 
$(3,3)=0.999$ 이고, 오른쪽은 $\operatorname{ICC}(3,3)=1$ 이다.

\section{4. 실험절차}

본 연구에서 $\mathrm{A}$ 와 $\mathrm{A}^{\prime}$ 는 기초선 기간과, $\mathrm{B}$ 의 로봇 중재 기간을 포함 전 체 중재 기간 동안 환자에게 기본적인 물리치료의 운동치료와 작업 치료가 진행되었다. B기간에 사용된 중재 방법은 기립경사로봇(RBOT+, NETBLUE, Korea)을 이용한 능동 보조 모드로써 하지의 45\% 보조를 통해 전체 체중의 $80 \%$ 만 싣도록 설정되었다(Figure 1). 그리고 화면에 자신의 발자국을 봄으로써 시각적 피드백을 받을 수 있으며, 자세한 중재 방법은 Table 2 와 같다. 본 연구에 사용된 로봇은 보행 시 수동, 능동, 능동 보조 및 저항 모드로 조건 설정이 가능하며, 체중지 지 안전벨트와 고정 장치로 인한 탈부하로 부분 체중지지의 정도를 보조화면을 통해 확인할 수 있다(Figure 2).

\section{5. 자료 분석}

본 연구에서 사용된 측정 방법의 측정자 간 신뢰도는 평가자 2 명의 일관성을 확인하기 위해 급내 상관계수로 분석하였다. 두 번의 기초 선과 중재 기간 동안 연구 대상자의 균형 변화를 알아보기 위해 시각 적 분석과 통계적 분석을 하였다. 시각적 분석은 연구의 결과를 그래
프로 나타내고, 통계적 분석에서는 경향선 접근 방법을 사용하여 그 래프에 경향선을 함께 나타내었다. 경향선 접근은 앞 구간에 비해 경 향선의 높이가 높고 낮음으로 중재의 효과를 판단할 수 있다.

\section{결 과}

\section{1. 기능적 팔 뻗기 검사}

두 번의 기초선과 한 번의 중재 기간 동안의 기능적 팔 뻗기 검사 시 에 균형 수준의 변화를 알아보기 위해 측정한 값을 Figure $3 \mathrm{~A}$ 에 제시 하였다. 대상자 1 은 중재 기간(B)의 평균 거리는 $41.28 \mathrm{~cm}$ 로 $27.7 \mathrm{~cm}$ 이 었던 기초선(A)에 비해 증가되었다. 중재가 끝난 기간인 기초선(A')에 도 평균거리는 $41.1 \mathrm{~cm}$ 로 기초선(A)에 비해 증가된 상태를 유지하고 있었다. 대상자 2는 중재 기간(B)의 평균 거리에서 $24.3 \mathrm{~cm}$ 로 $17.18 \mathrm{~cm}$ 이었던 기초선(A)에 비해 증가되었다. 중재가 끝난 기간인 기초선(A') 에도 평균거리는 $23.04 \mathrm{~cm}$ 로 기초선(A)에 비해 증가된 상태를 유지하 고 있었다.

\section{2. 왼발 한발 서기 검사}

두 번의 기초선과 한 번의 중재 기간 동안의 왼발로 지지하고 한발서
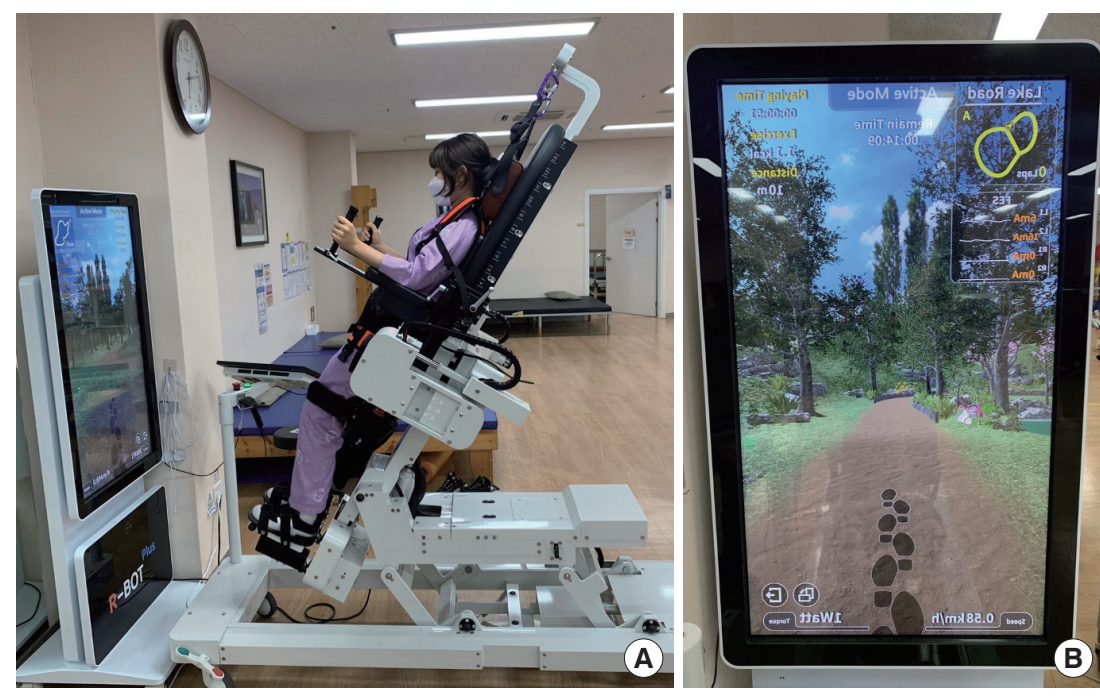

Figure 1. Robot intervention. (A) Side view during gait training using robot, (B) Provides visual feedback through footsteps.

Table 2. Intervention program

\begin{tabular}{|c|c|c|c|}
\hline interval & A (5 day) & B (5 day) & A' (5 day) \\
\hline intervention & \multicolumn{3}{|c|}{ Robot intervention (15 min) + bilateral hip joints cryotherapy (each 3 min) } \\
\hline & \multicolumn{3}{|c|}{ Robot setting: active mode, both leg $45 \%$ assist ratio, 35 step $/ \mathrm{min}, 50^{\circ}$ tilt. } \\
\hline & \multicolumn{3}{|c|}{$\begin{array}{l}\text { PT: exercise therapy (Total: } 150 \text { min, } 120 \text { min: ankle pumping, heel slide, quadriceps set, gluteal set, supine hip abduction, } \\
\text { short arc quad, long arc quad, straight leg raising, bridge exercise, standing hip flexion, standing hip abduction, standing } \\
\text { hip extension, mini-squat; } 30 \text { min: progressive resistance exercise) }\end{array}$} \\
\hline & \multicolumn{3}{|c|}{ OT: ADL intervention + education (Total: 90 min) } \\
\hline
\end{tabular}

PT: physical therapy, OT: occupational therapy, ADL: activities of daily living. 


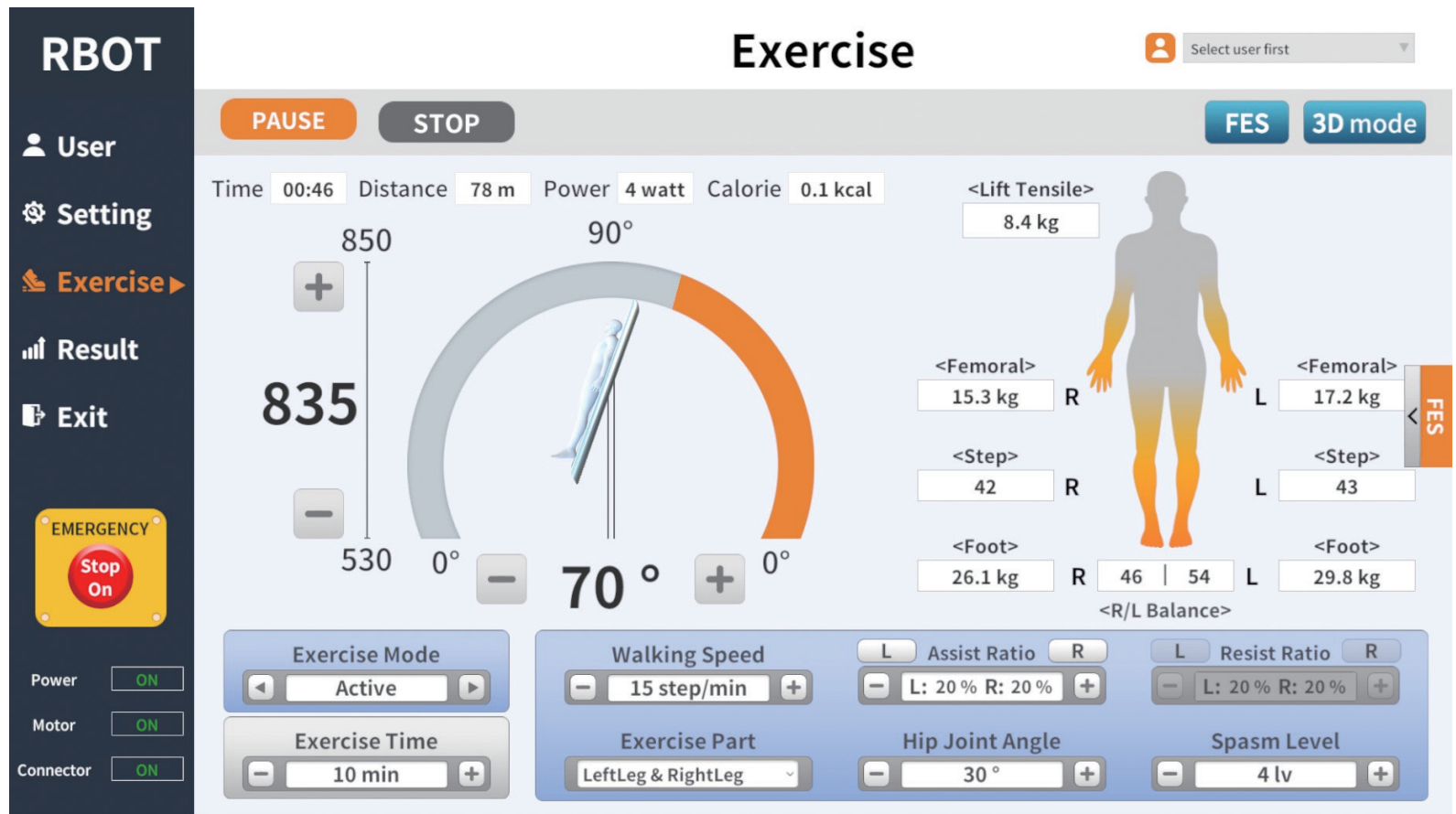

Figure 2. Robot assisted monitor. Active mode provides an assist ratio.

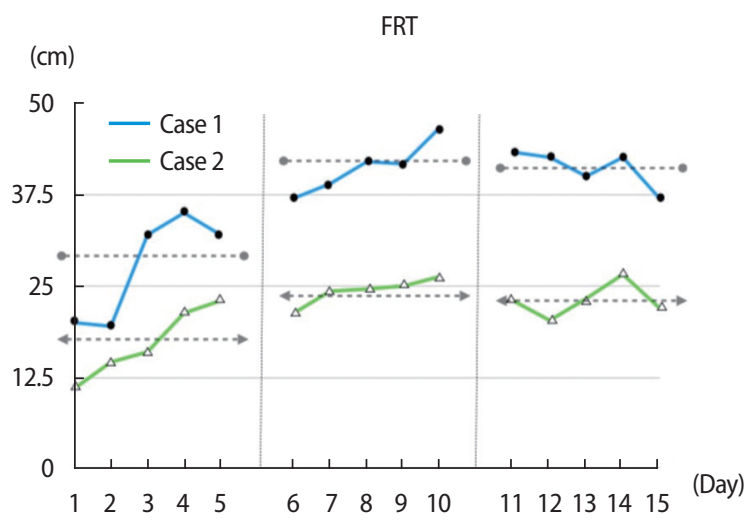

OLSTRT

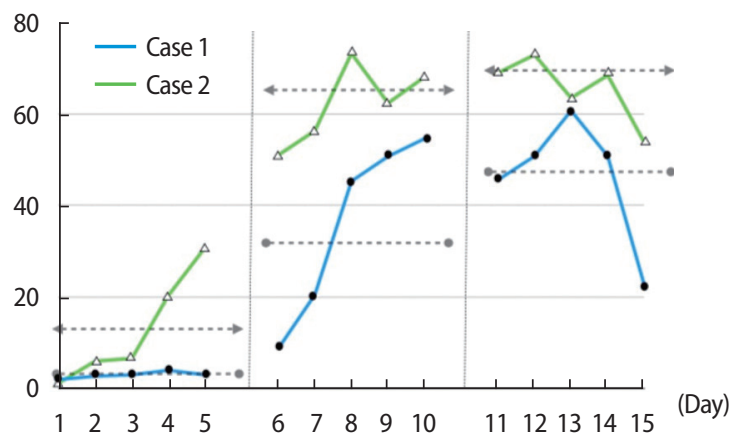

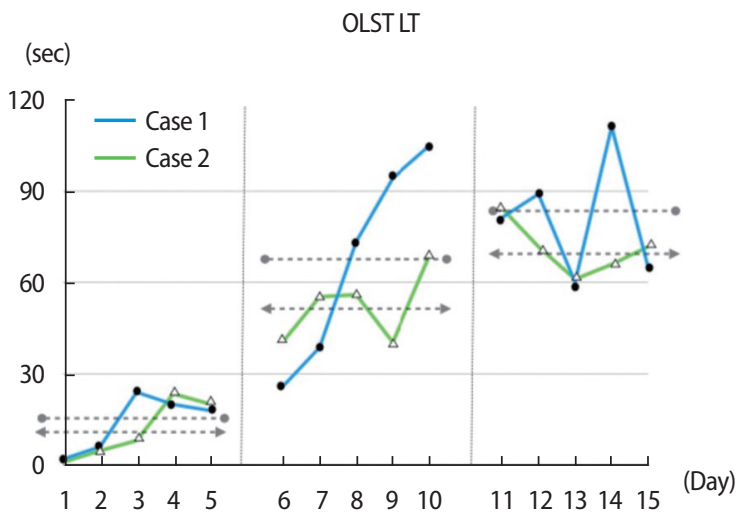

A

TUG

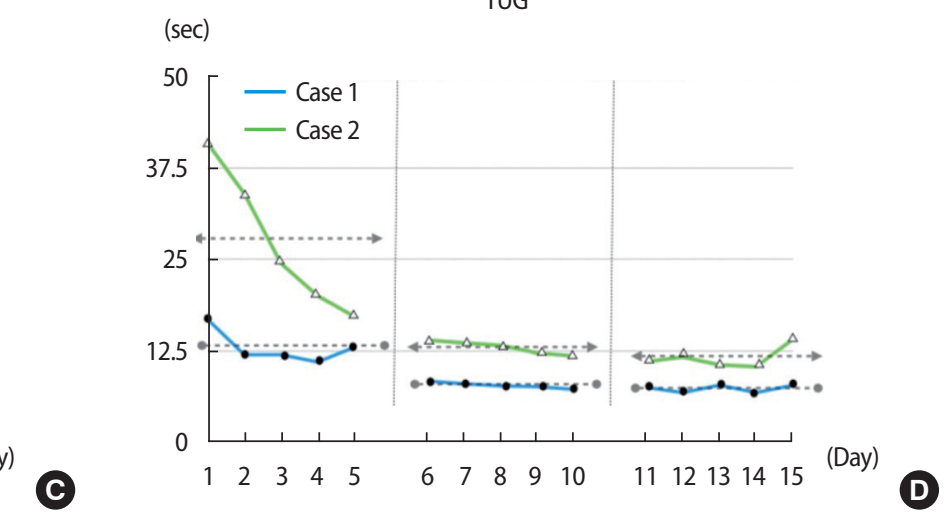

B

Figure 3. The difference between each period during results. (A) FRT of case1 and 2, (B) OLST LT of case 1 and 2, (C) OLST RT of case 1 and 2, (D) TUG of case 1 and 2. 
기시 균형 수준의 변화를 알아보기 위해 측정한 값을 Figure $3 \mathrm{~B}$ 에 제 시하였다. 대상자 1 은 중재 기간(B)의 평균 시간은 67.37 초로 14.03 초이 었던 기초선(A)에 비해 증가되었다. 중재가 끝난 기간인 기초선(A')에 도 평균시간은 81.22 초로 기초선(A)에 비해 증가된 상태를 유지하고 있었다. 대상자 2 는 중재 기간(B)의 평균 시간은 52.1 초로 11.53 초이었 던 기초선(A)에 비해 증가되었다. 중재가 끝난 기간인 기초선(A')에도 평균시간은 70.96초로 기초선(A)에 비해 증가된 상태를 유지하고 있 었다.

\section{3. 오른발 한발 서기 검사}

두 번의 기초선과 한 번의 중재 기간 동안의 오른발로 지지하고 한발 서기시 균형 수준의 변화를알아보기 위해 측정한 값을 Figure $3 \mathrm{C}$ 에 제시하였다. 대상자 1 은 중재 기간(B)의 평균 시간은 35.97 초로 2.94 초 이었던 기초선(A)에 비해 증가되었다. 중재가 끝난 기간인 기초선(A') 에도 평균시간은 46.07 초로 기초선(A)에 비해 증가된 상태를 유지하 고 있었다. 대상자 2 는 중재 기간(B)의 평균 시간은 62.19 초로 12.99 초 이었던 기초선(A)에 비해 증가되었다. 중재가 끝난 기간인 기초선(A') 에도 평균시간은 65.5 초로 기초선(A)에 비해 증가된 상태를 유지하고 있었다.

\section{4. 의자에서 일어나 걷기 검사}

두 번의 기초선과 한 번의 중재 기간 동안의 의자에서 일어나 걷기 검 사 시에 균형 수준의 변화를 알아보기 위해 측정한 값을 Figure 3D에 제시하였다. 대상자 1 은 중재 기간(B)의 평균 시간은 7.82 초로 12.96 초 이었던 기초선(A)에 비해 감소되었다. 중재가 끝난 기간인 기초선(A') 에도 평균시간은 7.37초로 기초선(A)에 비해 감소된 상태를 유지하고 있었다. 대상자 2 는 중재 기간(B)의 평균 시간은 12.99 초로 27.31 초이 었던 기초선(A)에 비해 감소되었다. 중재가 끝난 기간인 기초선(A')에 도 평균시간은 11.56 초로 기초선(A)에 비해 감소된 상태를 유지하고 있었다.

\section{고 찰}

본 연구에서는 기립 경사 로봇을 통한 보행 훈련이 AVN으로 인한 $\mathrm{THA}$ 를 시행한 2 명의 젊은 성인을 대상으로 균형에 미치는 영향을 알아보고자 하였다. 연구 결과 FRT, OLST, TUG에서 향상을 보였다. 두 대상자 모두 기초선에 비해 중재 기간에 균형 능력에 증가를 볼 수 있었고 중재 기간이 끝났음에도 그 상태를 유지하였다.

균형 능력을 기능적으로 해석하기 위하여 본 연구에서는 FRT를 사용하였고, 모든 대상자에게서 중재 기간의 향상도가 있었지만, 그 차이가 크지는 않았다. 수술을 받는 환자들은 대부분 불안을 느낀다
고 보고되었다. ${ }^{28}$ 국제 고관절 평가설문지(International Hip Outcome Tool, IHOT33)의 경우 5 번째 항목인 사회적, 감정적, 생활 형태에 관한 부분에서 대상자들은 $85 \%$ 의 불안감을 느낀다고 하였다. 그러므로, 로봇을 이용한 보행 중재가 시작되면서 환자의 불안이 줄어들었을 것이라고 생각된다. 대상자 1 에 비해 2의 경우 기초선과 중재기간의 차이가 크지 않았는데, 이는 대상자 2에게 있는 어깨관련질환에 의 한 통증의 영향을 받았을 것으로 보여진다.

OLST에서는 모든 대상자에게서 중재 시작일로(B)부터 눈에 띄는 향상을 보였고, 지지적인 부분에서 안정감이 생기면서 보행 시 나타 나는 흔들림이 줄어들었다. ${ }^{29} \mathrm{AVN}$ 환자의 보행 형태는 수술 전부터 통증으로 인한 몸통의 가쪽굽힘이 관측되고 이는 수술 후에도 이어 진다. ${ }^{8}$ 그리고 엉덩관절 주변의 근육 약화로 인해 통증이 개선 되었음 에도 비정상적인 보행(antalgic gait)이 지속된다. ${ }^{30}$ 기립 경사 로봇을 이 용한 보행 훈련은 체중의 $80 \%$ 를 지지할 수 있도록 조건 설정되어 좌 우의 균등한 지지를 만들어 준다. 로봇을 이용한 보행의 장점은 정확 한 보폭, 수치화된 체중 지지와 이동으로, ${ }^{31}$ 좌우의 균형을 유지할 수 있게 도와준다. 그러므로 양측 THA를 시행한 대상자의 지지부분에 서 상당한 도움이 되었을 것으로 판단된다. ${ }^{32}$ 체중부하와 자세안정성 을 강조하는 선행연구에서도 대상자의 체중 지지율이 $36.8 \%$ 의 향상 이 되었다고 보고 하였고, ${ }^{33} \mathrm{THA}$ 환자의 근력과 유연성 그리고 동적 균형이 중심 동요에 영향을 미쳐 체중지지율이 향상되었다고 해석한 선행연구와도 일치하는 것으로 나타났다. ${ }^{34}$ OLST LT 검사의 두번째 기초선(A') 기간에 대상자 1 의 경우 수치가 불규칙적으로 나타나는 것 은 대상자 1 에게 발생된 엄지 발가락의 통증이, 지지에 영향을 주었 을 것이라고 예상된다. ${ }^{35}$ 통증이라는 변수에 영향을 받았지만 초기 기초선의 평균값보다 증가된 상태를 유지하였다. 모든 결과값들이 대상자 2에 비해 대상자 1이 우세하였으나, OLST LT 검사의 경우 대 상자 2 에 비해 대상자 1 의 결과치가 현저히 낮은 것은, 수술 전 극심한 오른쪽 엉덩관절 통증이 원인으로 생각되어진다. 하지만 대상자 1 은 초기 기초선의 평균값보다 증가된 상태를 유지하였다.

균형 평가를 표준화하기 위해 사용하는 TUG에서는 모든 대상자 에게서 중재 기간의 향상도를 볼 수 있었다. ${ }^{36}$ 이는 기립 경사 로봇의 반복적인 움직임이 정확하게 나타나면서 대상자들의 지지 부분과 자신감의 향상을 만들어 주었을 것이다. ${ }^{19,37,38}$ 그로 인해 TUG시 정확 한 지지가 될 수 있게 도와주었고, 지지 시 몸통이 가쪽으로 기울어 지는 비정상적인 패턴을 줄여줌으로 균형 능력의 향상이 $\mathrm{TUG}$ 를 증 가하게 만들었을 것으로 생각된다. TUG 검사는 $3 \mathrm{~m}$ 의 거리에 있는 반환점을 안전하게 돌아야 하는데, 기초선 기간에 반환점을 불안하 게 돌아서는 모습을 보인 대상자들에게서 중재기간에는 비정상적인 패턴이 줄어든 안정적인 모습을 볼 수 있었다. ${ }^{37}$ 이는 보행과 균형 조 절 운동으로 구성된 운동 프로그램의 적용이 엉덩관절 안정성을 향 
상키는데 도움이 된다고 보고된 선행연구와 일치하다.39

본 연구에는 몇 가지 제한점이 있다. 첫째, 두 기초선에서 중재 기간

을 비교한 단일 사례 설계이므로 연구 결과를 일반화하는데 한계가 있다. 추후 연구에서는 보다 많은 대상자를 참여시켜 임상실험 설계

를 통한 중재 효과를 검증해야 한다. 둘째, 환자의 균형을 평가한 도구 가 모두 주관적 평가 도구가 사용되었다. 향후 연구에서는 균형을 객 관적으로 평가할 수 있는 도구 사용이 필요하다.

이상의 결과를 종합해 보면 양측 $\mathrm{THA}$ 를 시행한 30 대 환자에게서 로봇 재활이 균형에 긍정적인 영향을 미치는 것으로 나타났다. 이는 균형에 필요한 체중지지에서 매우 효과적이라고 할 수 있다. 따라서 본 연구는 일상으로 빠른 복귀가 필요한 THA를 시행한 환자에게 수 술 초기 로봇 재활의 적용이 매우 효과적인 방법이라고 생각된다.

\section{ACKNOWLEDGEMENTS}

이 논문은 2021년도 남부대학교 학술연구비의 지원을 받아 연구되었음.

\section{REFERENCES}

1. Moya-Angeler J, Gianakos A, Villa J et al. Current concepts on osteonecrosis of the femoral head. World J Orthop. 2015;6(8):590-601.

2. Kaushik AP, Das A, Cui Q. Osteonecrosis of the femoral head: an update in year 2012. World J Orthop. 2012;3(5):49-57.

3. Malizos KN, Karantanas AH, Varitimidis SE et al. Osteonecrosis of the femoral head: etiology, imaging and treatment. Eur J Radiol. 2007;63 (1):16-28.

4. Jang JD. Etiology and pathophysiology of osteonecrosis of the femoral head. J Korean Hip Soc. 2006;18(4):362-9.

5. Ancelin D, Rei na N, Cavaignac E et al. Total hip arthroplasty survival in femoral head avascular necrosis versus primary hip osteoarthritis: casecontrol study with a mean 10-year follow-up after anatomical cementless metal-on-metal 28-mm replacement. Orthop Traumatol Surg Res. 2016;102(8):1029-34.

6. Min K, Beom J, Kim BR et al. Clinical practice guideline for postoperative rehabilitation in older patients with hip fractures. Ann Rehabil Med. 2021;45(3):225-59.

7. Kim GB, Lee HS, Lee YJ et al. Case study of patients who underwent total hip arthroplasty. The Korean Nurse. 1997;36(4):34-50.

8. Cho SH, Lee SH, Kim KH et al. Gait analysis before and after total hip arthroplasty in hip dysplasia and osteonecrosis of the femoral head. J Korean Orthop Assoc. 2004;39(5):82.

9. Wareńczak A, Lisiński P. Does total hip replacement impact on postural stability? BMC Musculoskelet Disord. 2019;17:20(1):229.

10. Piscitelli P, Iolascon G, Di Tanna G et al. Socioeconomic burden of total joint arthroplasty for symptomatic hip and knee osteoarthritis in the Italian population: a 5-year analysis based on hospitalization records. Arthritis Care Res (Hoboken). 2012;64(9):1320-7.

11. ROOS, Ewa M. Effectiveness and practice variation of rehabilitation af- ter joint replacement. Curr opin Rheumatol. 2003;2:160-2.

12. Lee, GS, Lee SH, Park SH et al. Effect of postoperative intensive rehabilitation on ankle function recovery in patients with chronic ankle instability. Korean J Sports Med. 2020;38(1):20-7.

13. Nankaku M, Ikeguchi R, Goto K et al. Hip external rotator exercise contributes to improving physical functions in the early stage after total hip arthroplasty using an anterolateral approach: a randomized controlled trial. Disabil Rehabil. 2016;38(22):2178-83.

14. Austin MS, Urbani BT, Fleischman AN et al. Formal physical therapy after total hip arthroplasty is not required: a randomized controlled trial. J Bone Joint Surg Am. 2017;99(8):648-55.

15. Smedes F, Heidmann M, Keogh J. PNF-based gait rehabilitation-training after a total hip arthroplasty in congenital pelvic malformation; a case report. Physiother Theory Pract. 2021:1-10.

16. Beck H, Beyer F, Gering F et al. Sports therapy interventions following total hip replacement: a randomized controlled trial. Dtsch Arztebl Int. 2019;116(1-2):1-8.

17. Wijnen A, Bouma SE, Seeber GH et al. The therapeutic validity and effectiveness of physiotherapeutic exercise following total hip arthroplasty for osteoarthritis: a systematic review. PLoS One. 2018;13(3):e0194517.

18. Jun MH, Lee JH. Recent development of rehabilitation robots. J Korean Med Assoc. 2013;56(1):23-9.

19. Lee HJ, Lee SH, Seo K et al. Training for walking efficiency with a wearable hip-assist robot in patients with stroke: a pilot randomized controlled trial. Stroke. 2019;50(12):3545-52.

20. Kawasaki S, Ohata K, Yoshida T et al. Gait improvements by assisting hip movements with the robot in children with cerebral palsy: a pilot randomized controlled trial. J Neuroeng Rehabil. 2020;17(1):87.

21. Yoshioka T, Kubota S, Sugaya H et al. Feasibility and efficacy of knee extension training using a single-joint hybrid assistive limb, versus conventional rehabilitation during the early postoperative period after total knee arthroplasty. J Rural Med. 2021;16(1):22-8.

22. Tanaka Y, Oka H, Nakayama S et al. Improvement of walking ability during postoperative rehabilitation with the hybrid assistive limb after total knee arthroplasty: a randomized controlled study. SAGE Open Med. 2017;5:2050312117712888.

23. Koseki K, Mutsuzaki H, Yoshikawa K et al. Early recovery of walking ability in patients after total knee arthroplasty using a hip-wearable exoskeleton robot: a case-controlled clinical trial. Geriatr Orthop Surg Rehabil. 2021;12:21514593211027675.

24. Koseki K, Mutsuzaki H, Yoshikawa et al. Gait training using the honda walking assistive device in a patient who underwent total hip arthroplasty: a single-subject study. Medicina (Kaunas). 2019:14;55(3):69.

25. Duncan PW, Weiner DK, Chandler J et al. Functional reach: a new clinical measure of balance. J Gerontol. 1990:45(6):M192-7.

26. Rockwood K, Awalt E, Carver D et al. Feasibility and measurement properties of the functional reach and the timed up and go tests in the canadian study of health and aging. J Gerontol A Biol Sci Med Sci. 2000: 55(2):M70-3.

27. Giorgetti MM, Harris BA, Jette A. Reliability of clinical balance outcome measures in the elderly. Physiother Res Int. 1998:3(4):274-83.

28. Koo EJ, Kim JS. Effects of structured education program using CDROM on anxiety and self-care compliance in patients undergoing orthopedic spinal surgery. J Muscle and Health. 2011;18(1):39-49. 
29. Jung KS, Seo HD, Lee KW et al. The effect of change in gait speed on vertical force of the cane and distribution of affected foot in the persons with chronic stroke. J Korean Soc Phys Med. 2012;7(2):223-30.

30. Lee YJ. Essentials of musculoskeletal care. Seoul, Hanwoori, 2003:108-9.

31. Kim H, Kim JP. Development of an Intelligent legged walking rehabilitation robot. KSME. 2017;41(9):825-37.

32. Nantel J, Termoz N, Centomo H et al. Postural balance during quiet standing in patients with total hip arthroplasty and surface replacement arthroplasty. Clin Biomech (Bristol, Avon). 2008;23(4):402-7.

33. Trudelle-Jackson E, Smith SS. Effects of a late-phase exercise program after total hip arthroplasty: a randomized controlled trial. Arch Phys Med Rehabil. 2004;85(7):1056-62.

34. Trudelle-Jackson E, Emerson R, Smith S. Outcomes of total hip arthroplasty: a study of patients one year postsurgery. J Orthop Sports Phys Ther. 2002;32(6):260-7.
35. Clarke GR, Thomas MJ, Rathod-Mistry T et al. Hallux valgus severity, great toe pain, and plantar pressures during gait: a cross-sectional study of community-dwelling adults. Musculoskeletal Care. 2020;18(3):38390.

36. Browne W, Nair BKR. The timed up and go test. Med J Aust. 2019;210 (1):13-4.

37. Kim MK, Kim S, Kim SS. Effect of elastic resistive exercise combine with standard exercise protocol on lower extremity muscles strength and pain scales following total hip arthroplasty. KSSLS. 2007;31:901-9.

38. Kim JH, Kim OS. Balance confidence and balance ability among community-residing stroke patients. J Korean Biol Nurs Sci. 2010;22(4):4307.

39. Judge JO, Lindsey C, Underwood M et al. Balance improvements in older women: effects of exercise training. J Phys Ther. 1993;73(4):254-62. 